\title{
A synoptic climatology of surface-level ozone in Eastern Wisconsin, USA
}

\author{
G. J ay Lennartson ${ }^{1, *}$, M ark D. Schwartz ${ }^{2}$ \\ ${ }^{1}$ Department of G eography, University of N orth C arolina-G reensboro, G reensboro, N orth C arolina 27412-6170, USA \\ ${ }^{2}$ Department of G eography, University of Wisconsin-M ilwaukee, M ilwaukee, Wisconsin 53201, USA
}

\begin{abstract}
Areas in Eastern Wisconsin (EWI), USA, experience exceedances of the federal health standard for ozone each summer. Recent work from the Ozone Transport Assessment Group has provided support for the association between slowly migrating anticyclones over the Eastern United States and widespread amounts of high ozone throughout much of the region. Case studies have yielded additional evidence of this connection, and, further, have shown that synoptic-scale transport in association with this anticyclone can be an important factor in elevating ozone levels in EWI. A case study approach however is limited since only a small number of events can be analyzed. To address this deficiency, our investigation employed a synoptic climatology, which is capable of linking patterns of atmospheric circulation with patterns of tropospheric ozone over an extended period of time. To classify the atmospheric circulation a correlation-based scheme was applied to $30 \mathrm{yr}$ of gridded sea-levelpressure data. Our synoptic climatology showed that the highest ozone levels occurred when an anticyclone was present to the east of the Lake Michigan Air Quality Region (LMAQR); the same type of anticyclone identified by others as being responsible for the transport of regional-scale ozone and precursors to the LMAQR. Our synoptic climatology, therefore, supports the contention that the synopticscale transport of ozone from the Southern and Eastern US plays an important role in episodes of elevated ozone in EWI. Moreover, our results suggest that synoptic-scale systems (i.e. anticyclones situated over the Eastern US), which operate at much greater space and time scales than sub-regional scale circulations, are likely to transport sufficient ozone into Eastern WI to often exceed the new $8 \mathrm{~h}$, $80 \mathrm{ppb}$ health standard - unless steps are taken to reduce regional-scale emissions.
\end{abstract}

KEY WORDS: Tropospheric ozone $\cdot$ Synoptic climatology $\cdot$ M ap patterns

\section{INTRODUCTION}

\subsection{Air quality background}

A 6-county region of Eastern Wisconsin (EWI), USA, is one of a small group of metropolitan areas that have earned the federal government's 'severe' designation for ozone nonattainment areas (Weisensel \& Sagal 1991). Wisconsin (WI) counties with this rating are Kenosha, Milwaukee, Ozaukee, Racine, Washington, and Waukesha (Fig. 1).

Exceedance of the ozone standard is not limited geographically to EWI, but is rather a region-wide problem near Lake Michigan. This region-henceforth

*E-mail: gjlennar@uncg.edu referred to as the Lake Michigan Air Quality Region (LM AQR, Fig. 1)-experiences exceedances of the $1 \mathrm{~h}$, $120 \mathrm{ppb}$ ozone standard on about 10 to $20 \mathrm{~d} \mathrm{yr}^{-1}$ (LADCO 1995).

Ozone exceedances are a cause of great concern because elevated levels of this pollutant are associated with harmful effects on human health, vegetation, and several man-made and natural materials. High levels of ozone can cause headaches, dizziness, and impaired lung function (Cody et al. 1992). Several studies have shown a relationship between elevated levels of ozone and increased hospitalization (e.g. Burnett et al. 1997, Delfino et al. 1998).

Ozone is a secondary pollutant formed through a series of photochemical reactions involving oxides of nitrogen $\left(\mathrm{NO}_{\mathrm{x}}\right)$ and volatile organic compounds (VOCs)-ozone's precursors (LADCO 1995). (See 


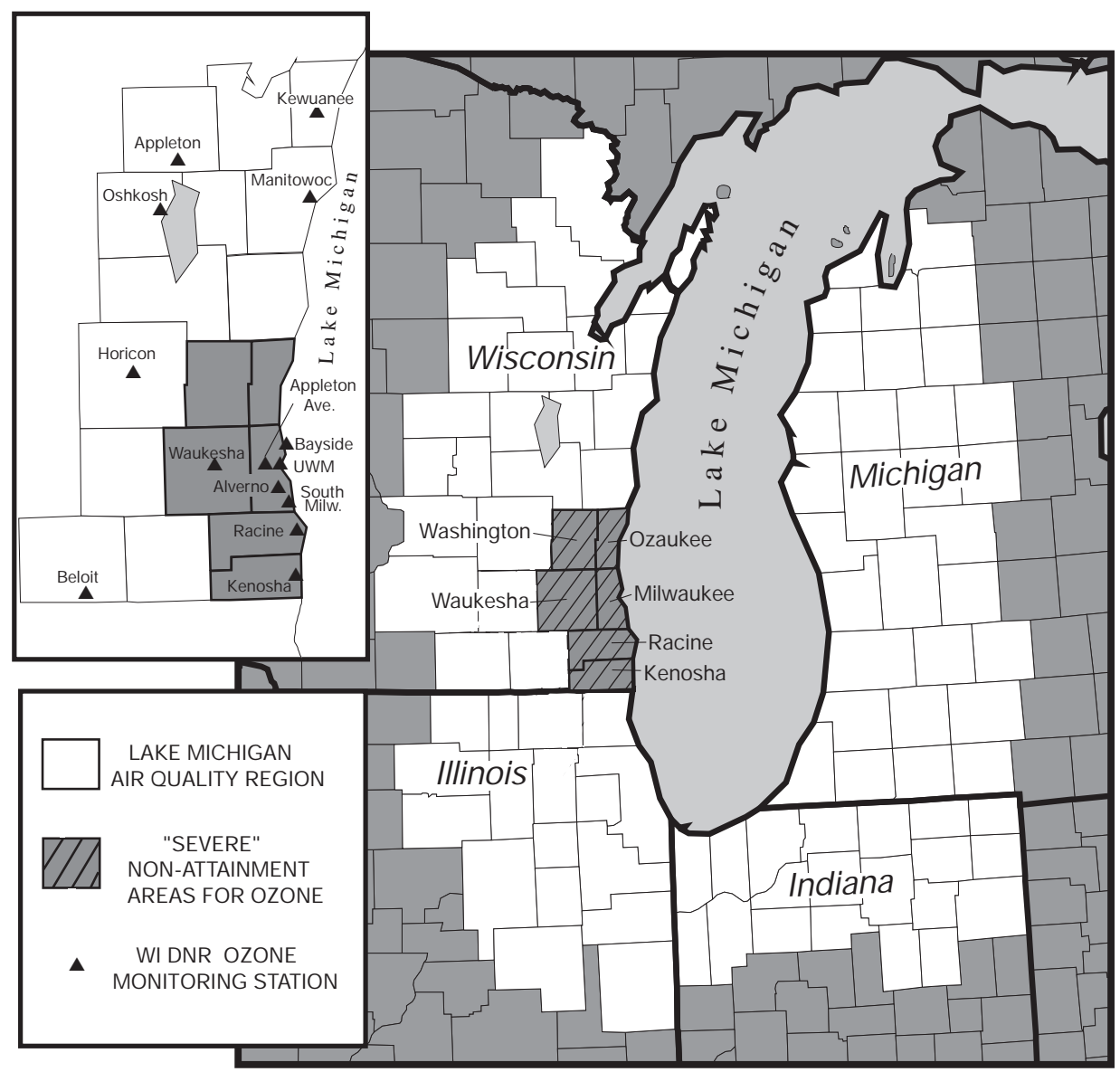

Fig. 1. Lake Michigan Air Quality Region; Eastern Wisconsin's 'severe' nonattainment counties for ozone; and Wisconsin Department of Natural Resources (WI DNR) ozone monitoring stations (inset)
Seinfeld [1989] for a detailed discussion of the basic reactions and relationships among the pollutant species involved in the production and destruction of ozone.) Major sources of VOCs include automobile emissions, gasoline and oil storage and transfer, and industrial use of such items as paint solvents, degreasing agents, cleaning fluids, and ink solvents. Fuel combustion in automobiles and power plants and processes used in chemical plants are primarly sources of $\mathrm{NO}_{x}$ (WI DNR 1997).

The concentration of ozone in an area is a function of the rate, type, and sources of emissions, as well as the state of the atmosphere (Oke 1987). Wind speed and direction, solar radiation, temperature, and mixing height are the meteorological conditions known to have the greatest influence on ozone concentrations (Lyons \& Cole 1976). On most summer days precursor emissions are generally similar and ozone levels are strongly influenced by meteorological conditions (Haney et al. 1989). On the whole then, daily variations in ozone concentrations may be treated as largely a fuction of changing meteorological conditions (Comrie 1992), which themselves are governed by the preval- ing synoptic-scale circulation (e.g. cyclones and anticyclones) (McKendry 1994).

\subsection{Ozone source areas and transport}

There are numerous upwind source areas for ozone and ozone precursor transport to EWI. At the subregional scale, source areas include the urban and industrial areas of Northern Indiana (i.e. Gary), Northeastern Illinois (i.e. greater Chicago), and Southeastern Wisconsin (i.e. greater Milwaukee) (Dye et al. 1995). On the synoptic (or regional) scale, it has been known for over $20 \mathrm{yr}$ that very large $(2000 \mathrm{~km}$ diameter) volumes of air in the Eastern US can become universally polluted with ozone (henceforth referred to as 'air-mass' ozone). These ozone-rich air masses are generally associated with anticyclones that are moving very slowly across the Eastern US (e.g. Wolff et al. 1977, Altshuller 1978, Vukovich \& Fishman 1986). Likely source areas of the ozone include the Northeast metropolitan area, Detroit, St. Louis, the Ohio River Valley, and parts of the Southern US (e.g. Lyons \& Cole 
1976, Wolff et al. 1977, Hanna \& Chang 1995). Air parcels within these highly polluted air masses can be transported thousands of kilometers over a time frame of several days (Lyons \& Cole 1976, Samson \& Ragland 1977). The clockwise air flow coming around the backside of a stagnant high pressure system situated over the Eastern US, which has traveled across several major ozone precursor producing areas, can thus bring elevated levels of ozone to areas within the Midwest (Lyons \& Cole 1976, Wolf \& Lioy 1980).

The connection between slow-moving anticyclones and elevated ozone across a large segment of an air mass has recently been reinforced by the Ozone Transport Assessment Group (OTAG). OTAG - a 2 yr (1995 to 1997) collaborative project between the US EPA, the 37 easternmost states and the District of Columbia, industry representatives, environmental groups, and researchers-evaluated the effects of the transport of ozone and its precursors on nonattainment areas in the Eastern US (Guinnup \& Collum 1997b). Their effort was motivated by an increasing awareness in the 1990s of the 'regional' nature of the Eastern states' ozone problems.

OTAG concluded that most widespread regionalscale ozone episodes in the Eastern US were associated with slow-moving anticyclones that produced light winds, high temperatures, abundant insolation, and limited vertical mixing. Additionally, they determined that the clockwise circulation of the anticyclone and its eastward migration is capable of transporting elevated ozone and precursors significant distances (Guinnup \& Collum 1997a). Further, high ozone levels in the northern portion of the OTAG domain, which includes EWI, were typically associated with intermediate ( 3 to $6 \mathrm{~m} \mathrm{~s}^{-1}$ ) and high $\left(>6 \mathrm{~m} \mathrm{~s}^{-1}\right.$ ) wind speeds and southerly winds $\left(90^{\circ}\right.$ to $\left.270^{\circ}\right)$ from inside the OTAG domain (Husar \& Renard 1997). Since during periods with higher wind speeds high concentrations of ozone are more likely attributable to regionally transported ozone (Husar \& Renard 1997), the implication is that elevated concentrations of ozone in the northern part of the OTAG domain during periods of higher winds, result from the regional-scale transport of ozone generated from elsewhere within the OTAG domain.

Hanna \& Chang (1995) also found evidence for the association between slowly eastward moving anticyclones in the Eastern US and high levels of ozone at the regional scale, and like OTAG were able to make a connection between air-mass ozone in the Eastern US and elevated ozone in EWI. Their findings were based on the analysis of 4 ozone exceedance episodes in EWI, which included measurements of ozone concentrations from aircraft flying along the southern (inflow) boundary of the LMAQR. They determined that during the high ozone events, polluted air with an ozone burden of 80 or $90 \mathrm{ppb}$ (just 30 to $40 \mathrm{ppb}$ less than the $1 \mathrm{~h}$ federal standard) was advected into the LMAQR. Their analysis (by eye) of National Weather Service surface weather maps and US EPA surface ozone maps revealed that each of the events took place when a surface high pressure system was situated over the Eastern US and a large ozone-rich air mass (with dimensions of 1000 to $2000 \mathrm{~km}$ ) was located near the center and to the west of the high. During the ozone episodes the LMAQR was thus subject to airflow with a southerly component and anticyclonic curvature which brought polluted air into the LMAQR from the south and east. Furthermore, Hanna \& Chang's (1995) analysis suggested that the pollutants were advected along trajectories originating in upwind source regions from St. Louis, through the Ohio River Valley, and into the Northeast US. Hanna \& Chang (1995), however, are quick to point out that their conclusions are the result of the examination of just 4 case studies - far too few to make broad generalizations.

From similarities between 2 case studies of ozone exceedances in the LMAQR, Dye et al. (1995) developed a generalized conceptual model of ozone formation and transport. An integral aspect of their conceptual model-consistent with the ideas of Hanna \& Chang (1995) and OTAG (Guinnup \& Collum 1997a) regards the link between ozone episodes in EWI and large ozone-rich high pressure systems to the east of the LM A QR. Dye et al. (1995) concluded that such systems transport in high concentrations of ozone and precursors from outside the $L M A Q R$, thereby raising ozone concentrations within the LM AQR, and increasing the likelihood of exceedances in EWI. It is important to emphasize, however, that like Hanna \& Chang's (1995) study, Dye et al.'s (1995) conclusions are based on a small number of cases.

\subsection{Investigative approach - objectives}

While 'case study' examinations like Hanna \& Chang (1995) and Dye et al. (1995) have significantly added to our understanding of EWI's ozone problem, there is a limiting factor inherent to this approach: only a small number of events can be analyzed. This is a crucial weakness, since designing an emission control strategy that will significantly lower ozone levels in EWI requires the identification of modes of atmospheric circulation most closely connected with high levels of ozone in EW. This can best be done by considering events over a period of several decades or longer.

To address this deficiency, a technique capable of linking patterns of atmospheric circulation with patterns of tropospheric ozone over an extended period of time is needed. We chose a synoptic climatological 
methodology for this investigation, which provides this linkage (Yarnal 1993).

Our approach allows: (1) climatological time-scale investigation of the general relationship between surface-level ozone and atmospheric circulation in EWI; and (2) more specifically, examination in a climatological context of Hanna \& Chang's (1995), Dye et al.'s (1995), and OTAG's findings regarding the association between between slow-moving high pressure systems in the Eastern US and elevated levels of ozone at the sub-regional scale-in particular, EWI.

\section{METHODOLOGY AND DATA}

\subsection{The classification scheme and gridded data}

Circulation classification is a developmental stage common to all synoptic climatologies (Barry \& Perry 1973). However, Yarnal (1993) showed that no single classification method was far superior to the others. Based on Yarnal's (1993) findings, and satisfactory performance in similar situations (e.g. Robinson \& Boyle 1979, M cKendry 1994), we decided to use the correlation technique. (See Yarnal [1984, 1993] for a more detailed discussion of this methodology.)

The correlation-based classification scheme was applied to gridded (12:00 h UTC) sea-level-pressure data for the months of M ay through September 1960 to 1988, and May and J une of 1989. These data were derived from the National Meteorological Center's (NMC's) 'Grid Point CDROM: Version II' (NCAR 1990). Out of a population of 4497 grids in the $30 \mathrm{yr}$ study period, only 39 grids were missing, leaving $4458 \mathrm{~d}$ for analysis.

A 6-by-6 grid - with a latitudinal resolution of $2.5^{\circ}$ and a longitudinal resolution of $5^{\circ}$-was chosen for this investigation. The grid domain extends from $37.5^{\circ}$ to $50^{\circ} \mathrm{N}$, and from $75^{\circ}$ to $100^{\circ} \mathrm{W}$. The 36 point grid is roughly centered on SE WI, and is of an appropriate size to capture synoptic-scale weather systems either situated just to the west of, centered over, or located to the east of the study area. We used Yarnal's sumsof-squares algorithm to compute the correspondence between each day's surface pressure patterns (Kirchhofer 1973, Yarnal 1984).

\subsection{Ozone data and map pattern - surface ozone analysis methods}

Ozone data used in this investigation are $1 \mathrm{~h}$ average concentrations from 14 stations in the Wisconsin Department of Natural Resource's (WI DNR) air quality monitoring network (Fig. 1, WI DNR 1997). They cover the time period May to September 1985 to 1988, and $M$ ay to J une 1989. Stations were chosen on the basis of record length, consistency, and time correspondence with gridded data.

An appropriate way to determine the degree to which each map pattern was associated with elevated ozone levels in EWI was to look at the frequency of exceedance days and the average-maximum value of ozone during occurrences of each map pattern. In this study, we defined an 'exceedance day' as a day in which 1 or more of the WI DNR's ozone monitoring stations reported an average-hourly concentration greater than or equal to $120 \mathrm{ppb}$. The 'average-maximum' value of ozone for each map pattern was obtained by: (1) determining each of the 14 station's highest average-hourly ozone concentration for a given day; (2) computing the average of the resultant 14 concentrations from Step 1; and (3) calculating the average of the concentrations from Step 2 for all days that belong to a particular map pattern. It was also useful to compute the 'cumulative dose of ozone maxima' for the map patterns. This was obtained by multiplying the frequency of the class by the average-maximum ozone value of the class. We also determined the 'departure of the mean cumulative dose', which provided an indication of a map pattern's 'relative positive or negative influence on the ozone climatology' of the study area (Yarnal 1993, p 137). Each pattern's 'percentage of the total cumulative dose of ozone maxima' was calculated as well. The 'total cumulative dose of ozone maxima' was just the sum of the cumulative dose of ozone maxima from all the map patterns.

To clarify the contribution of the respective map patterns to the higher order end of the ozone climatology spectrum, each of the patterns was ranked based on an equal weighting of the following 2 criteria: percent frequency of ozone exceedance days and mean-maximum ozone level.

\subsection{A pplication of Chang \& Hanna's (1993) classification scheme}

To further elucidate the atmospheric circulationsurface ozone connection in EWI, we also employed a 'manual' classification scheme developed by Chang \& Hanna (1993) (CH93). This classification scheme developed out of their analysis of the synoptic meteorology associated with four 1991 ozone episodes in the LMAQR. It is a version of M alm et al.'s (1989) classification scheme suggested for the Grand Canyon area, and was modified by Chang \& Hanna to better reflect the attributes of the LMAQR. Their scheme was chosen for our investigation because it is conceptually simplistic yet sufficiently robust to classify the map patterns 
developed from the correlation-based scheme. Moreover, their 3 synoptic types are based on the location of high pressure cells with respect to the LMAQR (Fig. 2), and, as mentioned earlier, we are interested in examining the connection between anticyclones in the Eastern US and elevated ozone in EWI. Each of the 16 map patterns resulting from the correlation-based classification scheme was manually examined to see if it met the criteria of any of the $3 \mathrm{CH} 93$ classes. Frontal positions were taken into consideration; however, our primary criterion for classification was the position of the anticyclone relative to the LM AQR.

The 3 classes that comprise Chang \& Hanna's (1993, p 5-69) scheme are as follows: (1) 'Front-of-High' (FH), on the 'front-side' or eastern side of a high pressure cell $-a$ front has just passed the LMAQR and the center of the high is located to the north or west of the Lake Michigan region, winds are light to moderate from a northerly direction, a mixed-layer of moderate depth is present, scattered cumulus clouds may be present, and lake breeze circulations may occur; (2) 'Center-of-High' $(\mathrm{CH})$, in the center of a high pressure cell - the Lake Michigan region is in or near the broad center of a high

Table 1. Results of the Kirchhofer scheme from the final classification, including the number of members, percent frequency, mean Kirchhofer score, and standard deviation (SD) of the Kirchhofer score of each map pattern for the period May to September 1960 to 1988, and M ay to J une 1989

\begin{tabular}{|lcccc|}
\hline $\begin{array}{l}\text { Map } \\
\text { pattern }\end{array}$ & $\begin{array}{c}\text { No. of } \\
\text { members }\end{array}$ & $\begin{array}{c}\text { \% } \\
\text { frequency }\end{array}$ & $\begin{array}{c}\text { Mean 'S' } \\
\text { score }\end{array}$ & $\begin{array}{c}\text { SD of the } \\
\text { 'S' score }\end{array}$ \\
\hline 1 & 603 & 13.5 & 9.7 & 5.0 \\
2 & 483 & 10.8 & 14.3 & 6.7 \\
3 & 333 & 7.5 & 12.3 & 5.3 \\
4 & 449 & 10.1 & 16.7 & 7.2 \\
5 & 220 & 4.9 & 12.1 & 5.4 \\
6 & 198 & 4.4 & 12.2 & 4.5 \\
7 & 216 & 4.8 & 15.2 & 6.3 \\
8 & 208 & 4.7 & 14.4 & 6.0 \\
9 & 172 & 3.9 & 13.3 & 5.4 \\
10 & 153 & 3.4 & 13.0 & 5.1 \\
11 & 170 & 3.8 & 14.2 & 5.6 \\
12 & 188 & 4.2 & 15.1 & 6.9 \\
13 & 170 & 3.8 & 18.6 & 6.9 \\
14 & 126 & 2.8 & 15.0 & 6.1 \\
15 & 177 & 4.0 & 16.0 & 6.4 \\
16 & 170 & 3.8 & 16.3 & 6.6 \\
\hline
\end{tabular}

pressure cell, winds are light and variable, skies are mostly clear, lake breeze circulations are likely, and there is strong stability above the mixed-layer; and (3) 'Back-of-High' (BH), on the 'back-side' of a high pressure cell - the Lake Michigan region is located on the western side ('western shoulder') of a high pressure system, winds are light to moderate from a southerly direction, a deep mixed-layer exists, scattered convective clouds may form, and lake breeze circulations are possible but may be inhibited by a strong synoptic flow.

\section{RESULTS AND DISC USSION}

\subsection{Classification results and map pattern attributes}

Upon final classification, $90.5 \%$ of the grids had been placed into 16 classes. This rate is comparable to other investigations (e.g. Yarnal 1993, McKendry 1994), especially since these prior studies used gridded sea-level-pressure data for all 12 mo instead of only the 5 consecutive warm season months used here. Summer circulation patterns are typically weaker and less well defined.

Table 1 shows the percent frequency of each of the 16 map patterns, along with the mean and standard deviation of their respective Kirchhofer scores. The mean Kirchhofer score for each of the map patterns is 
Table 2. Each map pattern's predominant surface flow, Chang \& Hanna (1993) class, 850 mb gradient wind direction near Eastern Wisconsin (WI), average maximum $1 \mathrm{~h}$ air temperature (Ta), average daily solar radiation (SR), and $500 \mathrm{mb}$ height contour characteristics ( $\mathrm{AC}$ is anticyclonic curvature; $\mathrm{CC}$ is cyclonic curvature). The mean of the average maximum $1 \mathrm{~h}$ temperature of all 16 map patterns is $72.9^{\circ} \mathrm{F}\left(22.7^{\circ} \mathrm{C}\right)$. The mean of the average daily solar radiation of all 16 map patterns is $21.2 \mathrm{MJ} \mathrm{m}^{-2}$

\begin{tabular}{|c|c|c|c|c|c|c|}
\hline $\begin{array}{l}\text { Map } \\
\text { Pattern }\end{array}$ & $\begin{array}{l}\text { Predominant } \\
\text { surface flow }\end{array}$ & $\begin{array}{c}\text { Chang } \& \\
\text { Hanna class }\end{array}$ & $\begin{array}{c}850 \mathrm{mb} \\
\text { gradient flow }\end{array}$ & $\begin{array}{c}500 \mathrm{mb} \\
\text { characteristics }\end{array}$ & $\begin{array}{c}\mathrm{Ta} \\
{\left[{ }^{\circ} \mathrm{F}\left({ }^{\circ} \mathrm{C}\right)\right]}\end{array}$ & $\begin{array}{c}S R \\
\left(M J \mathrm{~m}^{-2}\right)\end{array}$ \\
\hline 1 & SSW & $\mathrm{BH}$ & SW & $A C w /$ ridge axis $E$ of $W I$ & $79.1(26.2)$ & 19.7 \\
\hline 2 & WNW & & WNW & $\mathrm{CC} \mathrm{w} /$ trough axis $\mathrm{E}$ of $\mathrm{WI}$ & 74.7 (23.7) & 23.3 \\
\hline 3 & WSW & $\mathrm{BH}$ & WSW & Nearly zonal & 79.7 (26.5) & 20.6 \\
\hline 4 & $\mathrm{~N}$ & $\mathrm{FH}$ & $\mathrm{N}$ & $\mathrm{CC}$ w/trough axis $\mathrm{E}$ of $\mathrm{WI}$ & $65.1(18.4)$ & 20.5 \\
\hline 5 & SSW & $\mathrm{BH}$ & SW & $A C \mathrm{w} /$ ridge axis $\mathrm{E}$ of $\mathrm{WI}$ & $80.3(26.8)$ & 21.6 \\
\hline 6 & Indeterminate & $\mathrm{CH}$ & Indeterminate & AC w/ridge axis $\mathrm{W}$ of $\mathrm{WI}$ & $70.5(21.4)$ & 24.8 \\
\hline 7 & WSW & $\mathrm{BH}$ & WSW & $\mathrm{CC} \mathrm{w} /$ trough axis $\mathrm{W}$ of $\mathrm{WI}$ & $76.7(24.8)$ & 19.9 \\
\hline 8 & WSW & $\mathrm{BH}$ & W & $\mathrm{AC}$ w/ridge axis $\mathrm{W}$ of $\mathrm{WI}$ & $76.8(24.9)$ & 21.5 \\
\hline 9 & ESE & $\mathrm{BH}$ & SSW & $A C$ w/ridge axis $E$ of $W I$ & $74.0(23.3)$ & 17.1 \\
\hline 10 & SE & $\mathrm{BH}$ & Indeterminate & AC w/ridge axis through WI & $72.3(22.4)$ & 23.5 \\
\hline 11 & $\mathrm{E}$ & & Indeterminate & AC w/ridge axis through WI & $62.6(17.0)$ & 18.4 \\
\hline 12 & $\mathrm{E}$ & & Indeterminate & $\mathrm{AC}$ w/ridge axis $\mathrm{W}$ of $\mathrm{WI}$ & $62.8(17.1)$ & 18.2 \\
\hline 13 & SSW & $\mathrm{BH}$ & SW & $\mathrm{CC} \mathrm{w} /$ trough axis $\mathrm{W}$ of $\mathrm{WI}$ & $73.8(23.2)$ & 16.4 \\
\hline 14 & WSW & $\mathrm{BH}$ & W & $\mathrm{AC}$ w/ridge axis through WI & $84.1(28.9)$ & 24.2 \\
\hline 15 & NNE & & NNE & $\mathrm{AC} \mathrm{w} /$ ridge axis $\mathrm{W}$ of $\mathrm{WI}$ & $62.7(17.1)$ & 23.9 \\
\hline 16 & Indeterminate & $\mathrm{CH}$ & NNW & $\mathrm{AC} \mathrm{w} /$ ridge axis $\mathrm{W}$ of $\mathrm{WI}$ & $70.7(21.5)$ & 25.8 \\
\hline
\end{tabular}

significantly lower than the threshold value of 36 . This, in conjunction with the relatively small standard deviations, suggests that the resultant classification is robust (McKendry 1994).

When depicting the map patterns, rather than displaying the actual 'keydays' of each of the map patterns, it was decided that the map patterns would best be depicted as 'average surface-pressure patterns' - the average of all the grids associated with a particular keyday (Yarnal 1993, p 68). Table 2 provides a list of the attributes of the 16 map patterns. The items in Table 2 are included there because they have been shown (e.g. Dye et al. 1995, CH 93) to have a bearing on ozone levels in EWI. Among the attributes listed is the 'predominant' surface flow of each of the map patterns, their $\mathrm{CH} 93$ classification, and each pattern's average $1 \mathrm{~h}$ maximum temperature and average daily solar radiation (SR). The daily SR data used to compute the averages was generated from a semiphysical SR model (Petersen et al. 1995), using standard hourly meteorological observations from $\mathrm{Mil}$ il waukee, WI's Mitchell International Airport as input. Each map pattern's average $1 \mathrm{~h}$ maximum temperature was calculated by averaging maximum $1 \mathrm{~h}$ temperature data from EWI DNR monitoring stations. A pattern's 'predominant' boundary layer wind direction (or surface flow) in EWI was determined from an inspection of the orientation of a map pattern's isobars across EWI, and calculation of the percentage frequency of wind direction at EWI DNR monitoring sites on member days of a map pattern.

Because upper-level winds have been shown to have a bearing on surface ozone concentrations (e.g. McK- endry 1994), composites of the 850 and $500 \mathrm{mb}$ height fields for each of the map patterns were also generated. The $850 \mathrm{mb}$ level was chosen because it has been established that aged air-mass ozone can be stored overnight in the nocturnal residual layer (which can extend upward to $850 \mathrm{mb}$, or approximately $1500 \mathrm{~m}$ ) and then affect surface-level ozone concentrations of locations downwind the following day as convection taps ozone stored aloft in the residual layer and mixes it down to the surface (Zhang et al. 1998). The $500 \mathrm{mb}$ level was of interest because of its strong connection with the formation, strength, and location of synopticscale weather systems. Table 2 shows the gradient wind direction in EWI of each of the $850 \mathrm{mb}$ composite maps (based on a visual inspection of the height contours), and the characteristics of the height field of each of the $500 \mathrm{mb}$ composite maps.

A total of 7 of the 16 classes have predominant surface flow from the southwest (SSW or WSW): the most commonly occurring flow of the 16 patterns. This is reasonable since the most frequently observed wind direction at Milwaukee's Mitchell Field during the months of J uly, August, and September -3 of the 5 mo of our study period-is either from the SW of SSW (Knox 1996). Such a flow can result when an anticyclone is positioned to the SE of the LMAQR. At $850 \mathrm{mb}$, the southwesterly air stream is also the most frequently occurring flow. At the $500 \mathrm{mb}$ level, 11 of the 16 map patterns exhibit anticyclonic curvature of the height contours across the study area. Of the 11,5 map patterns have the axis of the ridge located to the west of WI, 3 show the axis of the ridge to the east of WI, and 3 
depict the axis of the ridge lying through WI. The location of the ridge axis relative to EWI is important because its position affects the location of the surface anticyclone, which impacts the direction of surface air flow across the study area, which in turn can have a bearing on ozone levels in EWI. The remaining 5 map patterns either displayed cyclonic curvature of the height contours or zonal flow.

Of the 16 map pattern classes, 9 possess criteria to be considered $\mathrm{CH} 93 \mathrm{BH}$ map patterns. Of the remaining map patterns, 2 are classed as $\mathrm{CH}$ patterns, and just 1 can be classified as a $\mathrm{CH} 93 \mathrm{FH}$ map pattern. As far as average $1 \mathrm{~h}$ maximum temperature is concerned, it ranges from a high of $84.1^{\circ} \mathrm{F}\left(28.9^{\circ} \mathrm{C}\right)$ in a $\mathrm{BH}$ map pattern with WSW surface flow to a low of $62.6^{\circ} \mathrm{F}\left(17^{\circ} \mathrm{C}\right)$ in a map pattern with predominant easterly surface flow. Values of SR vary from a high of $25.8 \mathrm{MJ} \mathrm{m}^{-2}$ in a $\mathrm{CH}$

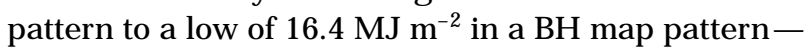
this was, however, a $\mathrm{BH}$ pattern with a low pressure area centered over WI, which would generate more cloud cover across EWI.

\subsection{M ap pattern - surface ozone relations}

An analysis of variance of the map patterns' meanmaximum ozone was found to be significant at the 0.001 level, indicating that the ozone levels associated with the map patterns were statistically different.
Recall that the patterns were to be ranked based on an equal weighting of percent frequency of ozone exceedance days and mean-maximum ozone. Since our investigation is primarily concerned with atmospheric circulation-ozone relationships during periods of high ozone in EWI, only the map patterns with a high ozone ranking are shown (see Fig. 3). Map Patterns 1,5 , and 14 all scored equally well and rank highest out of the 16 patterns (Table 3). They therefore are considered to be the 'preeminent' high ozone map patterns (PHOM Ps) and are displayed along with their 850 and $500 \mathrm{mb}$ composites in Fig. 3. Because of its high percentage frequency of exceedances and many similarities with the PHOM Ps, it was decided to show Map Pattern 8 and its 850 and $500 \mathrm{mb}$ composites in Fig. 3 as well. Map Patterns 1, 5, 14, and 8 are discussed in turn below.

\subsubsection{M ap Pattern 1}

M ap Pattern 1 (MP1) is the most frequently occurring pattern, with a frequency of $13.5 \%$ (Table 1). Of the 16 groupings, it has the lowest mean Kirchhofer score and second smallest standard deviation (Table 1), indicating that it is a particularly welldefined class. MP1 is significant because it appears to be quite representative of the type of synoptic-scale high pressure system that has been shown by OTAG,

Table 3. The percent frequency of ozone exceedance days (those days in which 1 or more WI DNR monitoring sites report an average-hourly $\mathrm{O}_{3}$ concentration greater than or equal to $120 \mathrm{ppb}$ ); the average-maximum $\mathrm{O}_{3}$ concentration; the cumulative dose of ozone maxima (obtained by multiplying the frequency of the class by the mean-maximum level of $\mathrm{O}_{3}$ ); the departure from the average cumulative dose (the mean cumulative dose of the 16 map patterns is $333.1 \mathrm{ppb}$ ) of all 16 map patterns; each map pattern's cumulative dose expressed as a percentage of the total cumulative dose (the total cumulative dose of the 16 map patterns is $5329.2 \mathrm{ppb}$ ); and each pattern's ranking on the basis of an equal weighting of its mean-maximum level of ozone and its percentage frequency of exceedances (the average mean-maximum value of ozone is $59.4 \mathrm{ppb}$ )

\begin{tabular}{|c|c|c|c|c|c|c|}
\hline $\begin{array}{l}\text { Map } \\
\text { Pattern }\end{array}$ & $\begin{array}{l}\% \text { frequency of } \\
\text { exceedance days }\end{array}$ & $\begin{array}{c}\text { Mean-maximum } \\
\mathrm{O}_{3}(\mathrm{ppb})\end{array}$ & $\begin{array}{l}\text { Cum. dose of ozone } \\
\text { maximum (ppb) }\end{array}$ & $\begin{array}{l}\text { Departure from mean } \\
\text { cum. dose }(\mathrm{ppb})\end{array}$ & $\begin{array}{l}\% \text { of total } \\
\text { cum. dose }\end{array}$ & $\begin{array}{l}\text { Map pattern } \\
\text { rank }\end{array}$ \\
\hline 1 & 27.8 & 71.8 & 971.2 & 638.1 & 18.2 & 1 \\
\hline 2 & 5.6 & 52.0 & 563.4 & 230.3 & 10.6 & 6 \\
\hline 3 & 5.6 & 62.1 & 463.9 & 130.8 & 8.7 & 3 \\
\hline 4 & 0.0 & 40.9 & 411.9 & 78.9 & 7.7 & 11 \\
\hline 5 & 16.7 & 81.9 & 404.2 & 71.1 & 7.6 & 1 \\
\hline 6 & 4.2 & 59.7 & 265.2 & -67.9 & 5.0 & 5 \\
\hline 7 & 4.2 & 52.5 & 254.4 & -78.7 & 4.8 & 6 \\
\hline 8 & 8.3 & 65.3 & 304.7 & -28.4 & 5.7 & 2 \\
\hline 9 & 2.8 & 64.4 & 248.5 & -84.6 & 4.7 & 4 \\
\hline 10 & 1.4 & 70.0 & 240.2 & -92.8 & 4.5 & 3 \\
\hline 11 & 1.4 & 52.5 & 200.2 & -132.9 & 3.8 & 8 \\
\hline 12 & 0.0 & 42.1 & 177.5 & -155.5 & 3.3 & 10 \\
\hline 13 & 5.6 & 55.7 & 212.4 & -120.7 & 4.0 & 5 \\
\hline 14 & 8.3 & 83.4 & 235.7 & -97.4 & 4.4 & 1 \\
\hline 15 & 0.0 & 43.0 & 170.7 & -162.4 & 3.2 & 9 \\
\hline 16 & 1.4 & 53.8 & 205.2 & -127.9 & 3.8 & 7 \\
\hline
\end{tabular}


a
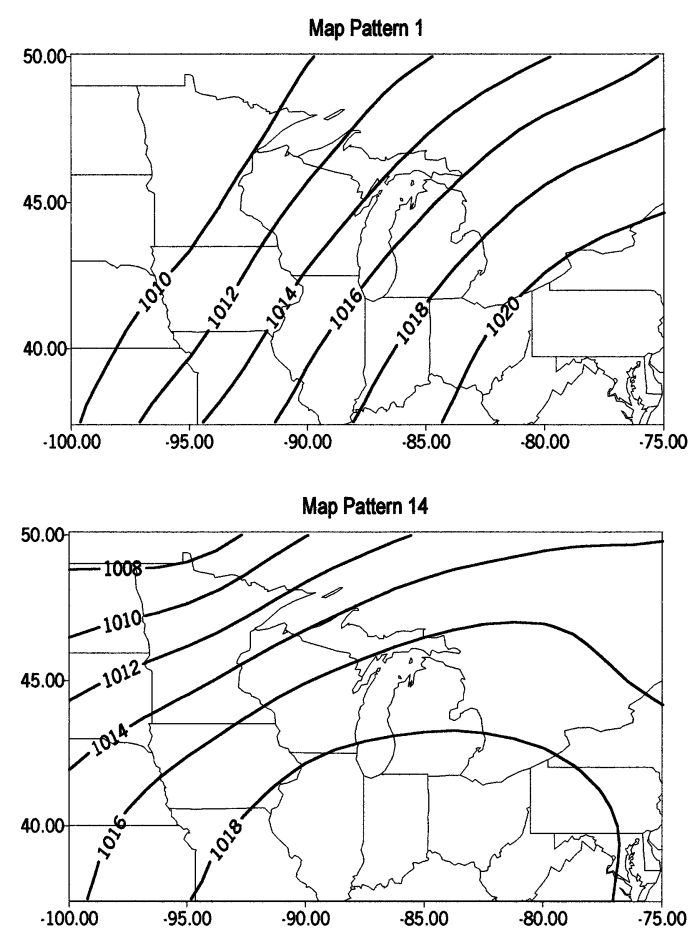

b
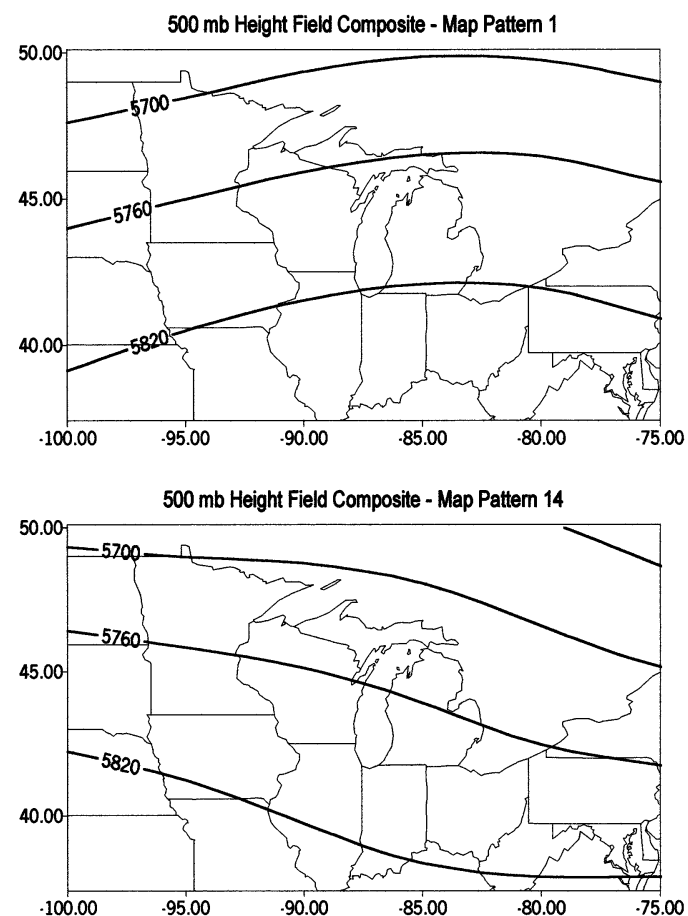
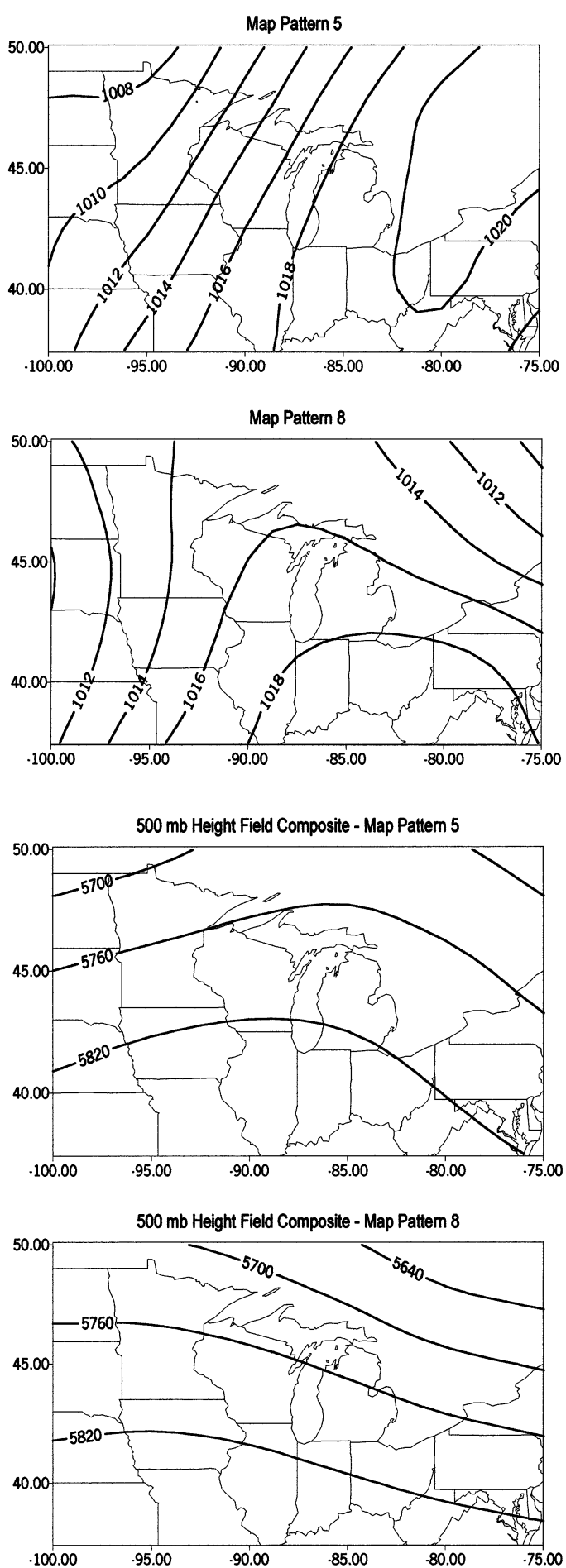

Fig. 3. (above and facing page) (a) Surface pressure map patterns most strongly associated with high ozone in Eastern Wisconsin (contour values are in millibars). (b) $500 \mathrm{mb}$ height composites for the high ozone map patterns. (c) $850 \mathrm{mb}$ height field composites for the high ozone map patterns (contour values are in meters)

Hanna \& Chang (1995), and Dye et al. (1995) to have an association with elevated ozone across a large segment of the Eastern US, as well as the LMAQR.
MP1 is characterized by an expansive and strong high pressure system which dominates the vast majority of the study area (Fig. 3a). The lobe of high pressure 
C
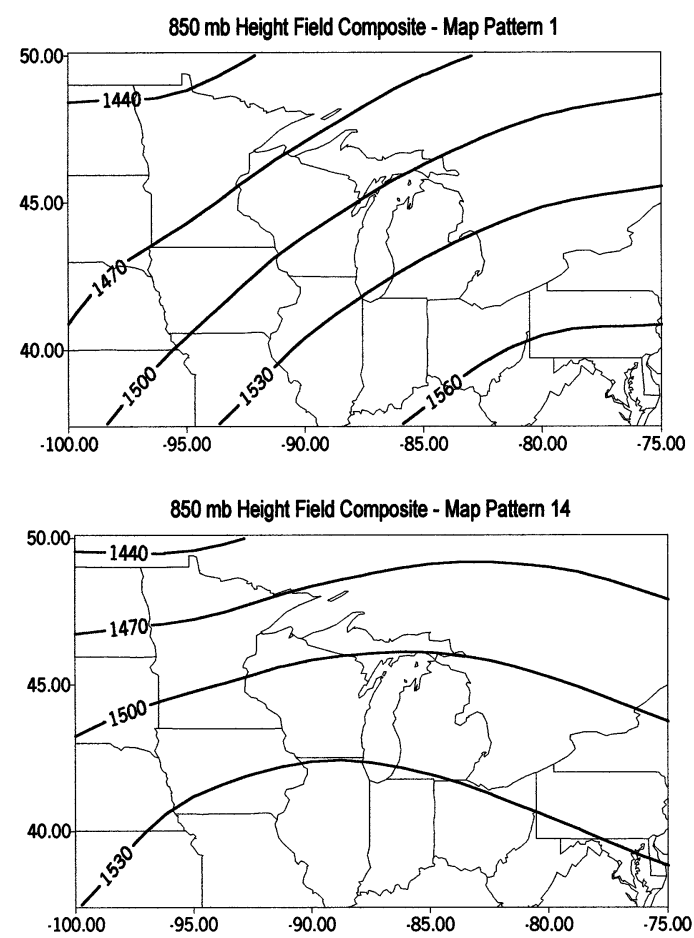

extending across much of the grid domain appears to be the western portion of a Bermuda High centered out over the Atlantic off the east coast of the US. This expansive high pressure system can be observed in the actual 'keyday' surface pressure map for this map pattern (Fig. 4). The geographic position and size of the anticyclone observed in MP1 (and it's keyday) agree closely with the position and size of OTAG's, Dye et al.'s (1995), and Hanna \& Chang's (1995) ozone-laden anticyclone. Additionally, M P1 corresponds well with $\mathrm{CH} 93$ s BH class.

A nother important characteristic of MP1 is the presence of a strong pressure gradient on the 'back-side' of the high. This gradient-along with the particular orientation of the isobars across EWI - allows for a moderately strong 'SSW' surface flow across EWI. (Wind directions enclosed in quotation marks are the the patterns' 'predominant' wind directions.) Recall that OTAG (more specifically, Husar \& Renard [1997] for OTAG) found an association between high levels of ozone in the northern portion of the OTAG domain and intermediate-to-strong winds from the 'southerly' direction-implying that the ozone had been transported in from outside the sub-region.

MP1 is also associated with relatively high levels of average maximum $1 \mathrm{~h}$ temperature $\left(79.1^{\circ} \mathrm{F}\left[26.1^{\circ} \mathrm{C}\right]\right)$ and average daily solar radiation (19.7 MJ m-2) - both of which have been shown by Hanna \& Chang (1995) and Dye et al. (1995) (among others) to be connected
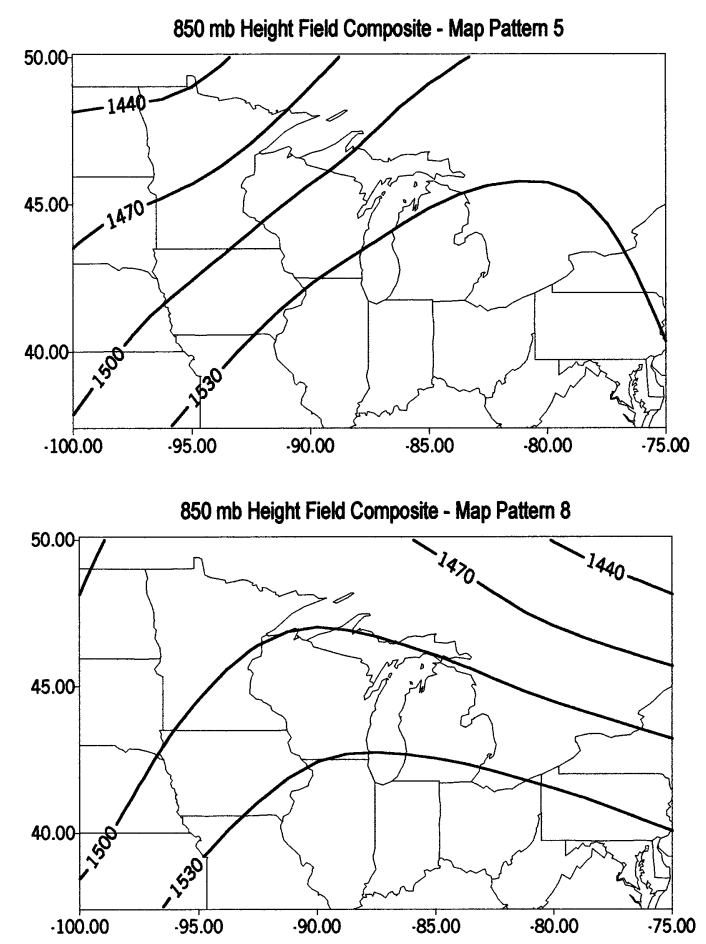

with elevated ozone in the Eastern US and the LMAQR.

In the $500 \mathrm{mb}$ composite map for MP1 (Fig. 3b), a ridge with its accompanying anticyclonic curvature dominates the entirety of the grid. EWI is located just upwind of the ridge axis. The well-developed $500 \mathrm{mb}$ ridge is responsible for the strong surface high. The $850 \mathrm{mb}$ composite map associated with M P1 (Fig. 3c) shows an area of high pressure anchored to the SE of WI. The high provides for a southwesterly gradient flow throughout the study area. Such a flow and pressure configuration at $850 \mathrm{mb}$ is noteworthy because the airstream upwind of EWI would have passed over a plethora of ozone and precursor sources, all adding to the concentration of ozone at the $850 \mathrm{mb}$ level. As mentioned earlier, these pollutants could be stored al oft in the nocturnal residual layer overnight and then brought down to the surface via convective mixing the following day, thereby increasing the concentration of surface-level ozone in EWI.

The aforementioned physical characteristics associated with MP1-characteristics shown by other researchers to be connected to elevated ozone in the LMAQR - are also shown here to be associated with very high levels of ozone. MP1 has the greatest frequency of exceedance days, almost twice that of the other patterns. The member days of MP1 account for nearly $28 \%$ of the 72 exceedance days during the study period (Table 3). MP1 also possesses an above average 
September 4, 1971 12:00 h UTC

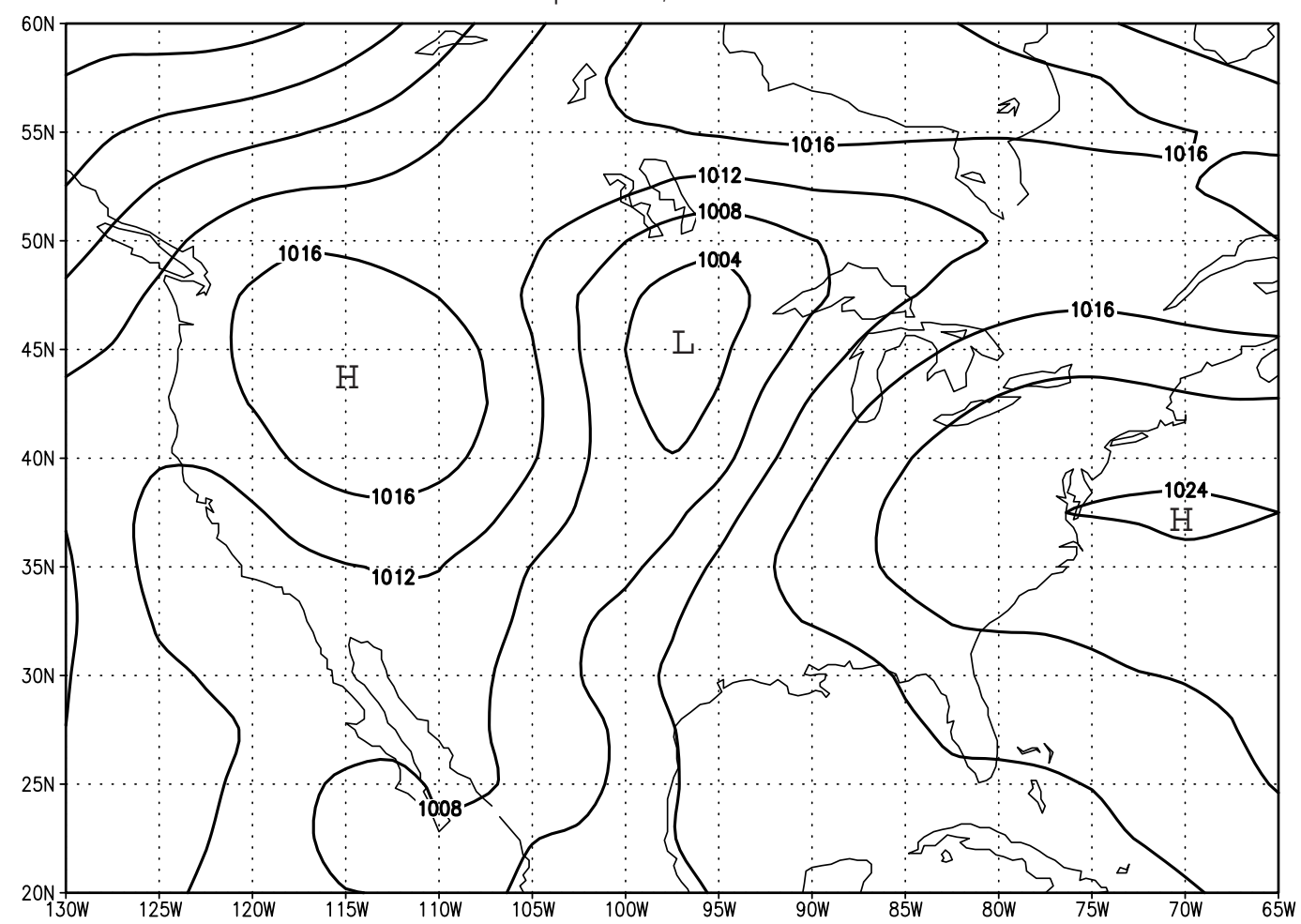

Fig. 4. 'Keyday' surface pressure map for Map Pattern 1

level of 'mean-maximum' ozone of $71.8 \mathrm{ppb}$ (the average mean-maximum ozone for all 16 patterns was $59.4 \mathrm{ppb}$ ). Its large positive value of the 'departure from the mean cumulative dose of ozone maxima' and high percentage (18\%) of the 'total cumulative dose of ozone maxima', means that it has a major 'relative positive' influence on the ozone climatology of EWI. MPI's large value of the cumulative dose of ozone maxima is due in part to its above average mean-maximum ozone, where it ranks third out of all the patterns, but more significantly to its high frequency of occurrence (Table 1 ).

\subsubsection{Map Pattern 5}

Map Pattern 5 (MP5) is also one of the PHOMPs in our study and has characteristics quite similar to those of MP1. Accordingly, M P5 is also very representative of the type of anticyclone that has been identified by Hanna \& Chang (1995), OTAG, Dye et al. (1995), and others with air-mass ozone in the Eastern US and elevated ozone in the LMAQR.

MP5 depicts a high pressure area centered to the east of WI, making it, like M P1, a BH map pattern. The orientation and packing of the slightly anticyclonically curved isobars across the eastern portion of WI indi- cates - as in MP1 - that a moderately strong 'SSW' air flow is present across EWI. With such a flow regime, and subsidence from the anticyclone to the east, high levels of sunshine and warm temperatures would be expected, and are what result. MP5 exhibits the second highest average maximum $1 \mathrm{~h}$ temperature of all the map patterns, $80.3^{\circ} \mathrm{F}\left(26.8^{\circ} \mathrm{C}\right)$, and a reasonably large value of average daily solar radiation of $21.6 \mathrm{MJ}$ $\mathrm{m}^{-2}$. Both values are higher than their respective counterparts in MP1.

The $500 \mathrm{mb}$ composite for M P5 is quite similar to that of $M P 1$, in that it features a ridge of high pressure that stretches across EWI, with EWI located just upwind from the ridge axis. MP5's $850 \mathrm{mb}$ composite-like MPl's - has a greater southwesterly component to it than does the surface air flow. The pressure gradient, and hence the flow in MP5's $850 \mathrm{mb}$ composite appears, however, to be somewhat weaker than that observed in MP1.

MP5's weaker flow at $850 \mathrm{mb}$ may be a factor in the lower number of exceedances associated with this pattern versus that of MP1, because with a weaker flow at $850 \mathrm{mb}$, the pollutants stored overnight in the nocturnal residual layer would be less concentrated, and thus smaller amounts of ozone could be delivered to the surface via convective mixing the following day. Never- 
Table 4. Map patterns and cumulative frequency of ozone exceedance days by predominant surface wind direction. Chang $\&$ Hanna's (1993) ‘Back-of-High' (BH), 'Center-of-High' (CH), and ‘Front-of-High' (FH) patterns are noted as well

\begin{tabular}{|lccccccccc|}
\hline $\begin{array}{l}\text { Surface wind } \\
\text { direction }\end{array}$ & NNE & E & ESE & SE & SSW & WSW & WNW & N & Indeterminate \\
\hline Map Patterns & 15 & 11,12 & $9(\mathrm{BH})$ & $10(\mathrm{BH})$ & $\begin{array}{c}1(\mathrm{BH}), 5(\mathrm{BH}), \\
13(\mathrm{BH})\end{array}$ & $\begin{array}{c}3(\mathrm{BH}), 7(\mathrm{BH}), \\
8(\mathrm{BH}) 14(\mathrm{BH})\end{array}$ & 2 & $4(\mathrm{FH})$ & $6(\mathrm{CH}), 16(\mathrm{CH})$ \\
$\begin{array}{l}\text { Cumulative } \\
\text { \% frequency }\end{array}$ & 0 & 1.4 & 2.8 & 1.4 & 50.1 & 26.4 & 5.6 & 0.0 & 5.6 \\
\hline
\end{tabular}

theless, MP5 has the second highest percentage frequency of exceedance days, $16.7 \%$, as well as the second highest value of mean-maximum ozone, $81.9 \mathrm{ppb}$. Additionally, it has a relative positive influence on the ozone climatology of the study area (based on its positive value for the departure from the mean cumulative dose), and is responsible for $7.6 \%$ of the total cumulative dose of ozone. Thus, M P5, like M P1, plays a significant role in the ozone climatology of EWI, and further, is closely associated with elevated levels of surfacelevel ozone.

\subsubsection{M ap Pattern 14}

Map Pattern 14 (M P14) is the last of the PHOMPs, and like $M$ ap Patterns 1 and 5 , has attributes that are comparable in many regards to those of the ozoneladen anticyclones (air-mass ozone anticyclones, 'AMOAs') of other researchers (e.g. Dye et al. 1995, Hanna \& Chang 1995, Zhang et al. 1998, and OTAG).

Surface air flow and geographic position are 2 of the physical characteristics that MP14 and the AMOAs have in common. A 'WSW' surface flow is present across EWI in M P14. It results from the juxtaposition of a broad and relatively weak area of high pressure located to the south and east of WI, with an area of low pressure situated in South-Central Canada. Because of the geographic position of the high, MP14, like MP1 and MP5, can be classed as a $\mathrm{CH} 93 \mathrm{BH}$ map pattern. Not only does the surface flow in the vicinity of EWI in M P14 have a greater westerly component to it than that of Patterns 1 and 5, but also, its flow is not quite as strong as that of $\mathrm{MP1}$ and MP5.

A high pressure ridge is present across the study area at $850 \mathrm{mb}$. The gradient wind flow throughout EWI at $850 \mathrm{mb}$ appears to be predominantly from the west, and, like MP5's $850 \mathrm{mb}$ flow, is weaker than that observed in $\mathrm{MP1}$. At $500 \mathrm{mb}, \mathrm{EWI}$ is under the influence of a weak ridge of high pressure, with the axis of the ridge lying over WI.

M P14 is associated with high levels of temperature and insolation. Of the 16 map patterns, it exhibits the highest value of average maximum $1 \mathrm{~h}$ temperature, $84.1^{\circ} \mathrm{F}\left(28.9^{\circ} \mathrm{C}\right)$, and the third largest amount of average daily solar radiation, $24.2 \mathrm{MJ} \mathrm{m}^{-2}$. The high levels of temperature and radiant energy, indubitably, are a factor in M P14's high ozone levels. M P14 has the highest level of mean-maximum ozone of all the patterns, $83.4 \mathrm{ppb}$, and is responsible for a relatively high percentage of the exceedance days in our study, 8.3\%. This, however, is a smaller percentage than that found in MPI and MP5, which may result, at least in part, from the weaker surface flow of MP14, in comparison to that of MP1 and MP5. Lastly, in contrast to MP1 and MP5, MP14 has a relative negative influence on the ozone climatology of the study area because of its small frequency of occurrence.

\subsubsection{Other map pattern-surface ozone relationships}

M ap Pattern 8 (MP8), while not regarded as one of the PHOMPs, ranks second in mean-maximum ozone and percent frequency of exceedance days, and has a number of attributes in common with the 3 PHOMPs, as well as with the archetypal AMOA. As an example,

Table 5. Map pattern; cumulative percent frequency of exceedance days; cumulative percent of the total cumulative dose of ozone; and average mean-maximum ozone-by Chang \& Hanna's (1993) map pattern

\begin{tabular}{|lccc|}
\hline & $\begin{array}{c}\text { Front of high } \\
\text { map patterns }\end{array}$ & $\begin{array}{c}\text { Center of high } \\
\text { map patterns }\end{array}$ & $\begin{array}{c}\text { Back of high } \\
\text { map patterns }\end{array}$ \\
\hline Map Patterns & 4 & 6,16 & $\begin{array}{c}1,3,5,7,8, \\
9,10,13,14 \\
80.7\end{array}$ \\
$\begin{array}{l}\% \text { frequency of } \\
\text { ozone exceedances } \\
\% \text { of total cumulative } \\
\text { dose of } \mathrm{O}_{3} \\
\begin{array}{l}\text { Mean-maximum } \\
\text { ozone (ppb) }\end{array}\end{array}$ & 7.7 & 5.6 & 62.6 \\
\hline
\end{tabular}


M P8 features a large dome of high pressure anchored just to the southeast of the Ohio River Valley, and thus can be classed as a BH map pattern. In particular, M P8 is similar in many regards to M P14 (see Table 2), and has the same percentage frequency of exceedance days as MP14, $8.3 \%$. Its value of mean-maximum ozone, however, is considerably smaller, only $65.3 \mathrm{ppb}$, which gives MP8 its second place ranking for ozone level. MP8's lower temperatures as compared to M P14's, may explain, at least in part, its lower value of mean-maximum ozone.

Of the remaining map patterns, only M ap Patterns 2, 3 , and 13 are associated with a relatively high percentage (5.6\% each) of the exceedance days. Their respective values of mean-maximum ozone are relatively low though. In total, 2 of the 3 patterns, M ap Patterns 3 and 13 , have several attributes in common with the AMOA, M P8, and the PHOM Ps. One important difference between them, however, is the lack of a well-developed ridge over $\mathrm{EWI}$ at $500 \mathrm{mb}$.

To further understand ozone-map pattern relations in EWI, it was useful to group the map patterns according to their predominant surface flow across the study area, and then to calculate each surface-flow category's cumulative percentage frequency of exceedance days. From Table $4,50.1 \%$ of the ozone exceedances are produced by the 3 map patterns-Map Patterns 1, 5, and 13-with 'SSW' flow. If one considers both the 'SSW' and 'WSW' map patterns, over $75 \%$ of the exceedances are accounted for. These findings are noteworthy because, as mentioned earlier, surface flow with a 'southerly' component has been connected by other researchers (e.g. OTAG) with elevated ozone in EWI, and, further, is an attribute of the AMOA.

The strong connection between high ozone levels in EWI and AMOAs was accented to an even greater degree when the map patterns from our study were grouped according to their $\mathrm{CH} 93$ class. From Table 5, BH map patterns-which are predominately 'SSW' and 'WSW' patterns (Table 4)-are responsible for $80.7 \%$ of the exceedance days, $62.6 \%$ of the total cumulative ozone dose for the study area, and have a combined average for mean-maximum ozone of $67.5 \mathrm{ppb}$. In stark contrast, the $\mathrm{CH}$ map patterns are connected with just $5.6 \%$ of the exceedance days, produce $8.8 \%$ of the total cumulative dose of ozone, and have an average mean-maximum ozone of $56.8 \mathrm{ppb}$; the sole FH pattern, Map Pattern 4, is not associated with any exceedances, is responsible for only $7.7 \%$ of the total cumulative dose of ozone, and has a value of mean-maximum ozone of just $40.9 \mathrm{ppb}$. These results show clearly that the $\mathrm{BH}$ patterns-map patterns that have many of the same attributes as those found in association with the 'classic' AMOA-are strongly associated with high levels of ozone in EWI.

\section{SUMMARY AND CONCLUSIONS}

Our synoptic climatology of surface-level ozone in EWI-derived from a standard correlation-based classification scheme as applied to a $30 \mathrm{yr}$ period of National M eteorology Center (NMC) grid point dataproduced 16 distinctive map patterns. Specific attributes of each of the map patterns and their corresponding 850 and $500 \mathrm{mb}$ composites were examined carefully, with an eye toward identifying and characterizing those attributes that play an important role in the ozone climatology of EWI.

We focused on the map patterns with the highest ozone level because they are most likely to be associated with exceedances of the NAAQS (National Ambient Air Quality Standards). We determined-based on the map patterns' frequency of exceedance days and mean-maximum ozone levels - that $M$ ap Patterns 1, 5, and 14 were the PHOM Ps, with Map Pattern 8 following closely behind. It is significant that each of these patterns has attributes that are quite similar to those found in association with the archetypal AMOA: an anticylone type that has been shown by Hanna \& Chang (1995), Dye et al. (1995), and OTAG (among others) to be associated with elevated ozone in the LMAQR. In particular, the geographic position of the high in Map Patterns 1, 5, 14, and 8 agree well with the geographic position of the AMOA. There is also agreement in the area of surface-level air flow: both the AMOA and M ap Patterns 1, 5, 14, and 8 bring a southwesterly surface flow to EWI. Additionally, both the AMOA and the PHOM Ps are associated with relatively high levels of solar radiation and temperature. The strong connection between the AMOA and elevated ozone in EWI was further reinforced when we classified the 16 map patterns on the basis of: (1) their $\mathrm{CH} 93$ class and (2) their predominate surface flow. Over $80 \%$ of the exceedance days were accounted for by $\mathrm{BH}$ map patterns - which are representative of the AM OA; and we determined that the predominate map patterns associated with elevated ozone in EWI are those which exhibited southwesterly ('SSW' or 'WSW') surface flow across $E W I-a$ flow characteristic of AMOAs.

Examination of the $500 \mathrm{mb}$ composites of each of the map patterns revealed that the preeminent high ozone map patterns, plus M P8, occurred in association with a with a well-developed ridge over EWI. In the case of Map Patterns 1 and 5-the 2 map patterns showing the highest ozone levels - the axis of the ridge was displaced to the east of WI, whereas in Map Patterns 14 and 8-map patterns with lower ozone levels-the axis of the ridge was situated over or just to the west of WI. A reasonable inference that may be drawn from this is that higher ozone levels in WI occur when the surface anticyclone is displaced farther to the east as a 
result of the eastward displacement of the ridge. Inspection of the $850 \mathrm{mb}$ composites showed that the patterns with the highest ozone levels, Map Patterns 1 and 5 , were accompanied by southwesterly flow at $850 \mathrm{mb}$, while the patterns with lower ozone levels, M ap Patterns 8 and 14, exhibited $850 \mathrm{mb}$ flow that was weaker and had a stronger westerly component to it. From this, it is possible to infer that a SW air stream at $850 \mathrm{mb}$ over EWI is more ozone laden than a more westerly oriented air flow: perhaps because the SW air stream passes over a greater number of source areas.

We also noted that the map patterns with the highest levels of ozone-M ap Patterns 1 and 5-exhibited the strongest southwesterly surface flow of all the map patterns. Being that the regional-scale transport of ozone is more likely when winds are stronger (Husar \& Renard 1997), one inference that may be drawn is that the high levels of ozone exhibited by M ap Patterns 1 and 5 result (to some degree) from the transport of ozone generated from sources outside of the LMAQR.

While it was not the intent of our investigation to explore directly the subject of ozone transport into the LMAQR, and, indeed, other methodologies are better suited to address this issue, the fact that EWI's highest levels of ozone occur in the presence of AMOAs and southwesterly flow at both the surface and $850 \mathrm{mb}-$ elements which are conducive to the regional-scale transport of ozone and precursors to EWI-certainly suggests that a significant portion of the ozone present in EWI during ozone episodes originates from outside of the LMAQR. Our synoptic climatology therefore supports the case study findings of Hanna \& Chang (1995) and Dye et al. (1995), as well as the work of OTAG, that high ozone events in EWI occur in association with AMOAs, and, as a result, polluted air from the Southern and Eastern US is advected into the LMAQR and is a contributor to episodes of elevated ozone in EWI.

Our findings are particularly relevant considering recent changes in level and averaging period within the ozone standard. Previous work (e.g. Dye et al. 1995) has shown that sub-regional-scale elementsthe unique meteorology of the LMAQR and the strong stability of the conduction layer over Lake Michigan-are necessary factors in exceedances of the old $1 \mathrm{~h}, 120 \mathrm{ppb}$ standard. Our results suggest that synoptic-scale systems (i.e. AMOAs), which operate at much greater space and time scales than sub-regional-scale circulations, are likely to transport sufficient ozone into EWI to often exceed the new $8 \mathrm{~h}, 80 \mathrm{ppb}$ standard. Investigations of ozone transport at the synoptic scale should continue including proposals to reduce interstate transport. The regional control program for nitrogen oxides (EPA 1998) is a first step in this direction.

\section{LITERATURE CITED}

Altshuller AP (1978) Association of oxidant episodes with warm stagnating anticyclones. J Air Pollut Control Assoc 28:152-155

Barry RG, Perry AH (1973) Synoptic climatology. Methuen, London

Burnett RT, Brook J R, Yung WT, Dales RE, Krewski D (1997) Association between ozone and hospitalization for respiratory diseases in 16 Canadian cities. Environ Res 72(1): 24-31

Chang J C, Hanna SR (1993) Surface meteorological data and synoptic meteorology during 1991 LMOS ozone episodes. Report No. 1197-405/406. Sonoma Technologies, Santa Rosa, CA

Cody RP, Weisel CP, Birnbaum G, Lioy PJ (1992) The effect of ozone associated with summertime photochemical smog on the frequency of asthma visits to hospital emergency departments. Environ Res 58(2):184-194

Comrie AC, Yarnal B (1992) Relationships between synopticscale atmospheric circulation and ozone concentrations in metropolitan Pittsburgh, Pennsylvania. Atmos Environ 26(3):301-312

Delfino RJ , M urphy-M oulton AM, Becklake M R (1998) Emergency room visits for respiratory illnesses among the elderly in Montreal: association with low level ozone exposure. Environ Res 76(2):67-77

Dye TS, Roberts PT, Korc ME (1995) Observations of transport processes for ozone and ozone precursors during the 1991 Lake Michigan Ozone Study. J Appl Meteorol 34: 1877-1889

EPA, Office of Air Quality Planning and Standards (1998) Fact sheet: final rule for reducing regional transport of groundlevel ozone (9/24/98). http://www.epa.gov/ttn/oarpg/ tlfs.html

Guinnup D, Collom B (1997a) Final report for the OTAG Air Quality Analysis Workgroup; volume II: summary and integration of results. http://capita.wustl.edu/Otag/ Reports/ExexSumm 5 8 97/Sum vol2.html

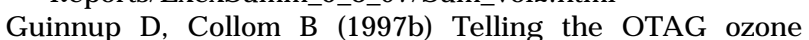
story with data. http://capita.wustl.edu/OTAG/Reports/ AQAfinVol_I/HTML/V1_exsum7.html

Haney J L, Doūglas SG, Chinkin LR, Souten DR, Burton CS, Roberts PT (1989) Ozone air quality scoping study for the lower Lake Michigan Air Quality Region. Rep. SYSAPP89/113, Systems A pplication, Inc, San Rafel, CA

Hanna SR, Chang J C (1995) Relations between meteorology and ozone in the Lake M ichigan area. J Appl M eteorol 34: 670-678

Husar RB, Renard WP (1997) Ozone as a function of local wind direction and wind speed: evidence of local and regional transport. http://capita.wustl.edu/otag/Reports/ OTAGWIND/OTAGWIND.html

Kirchhofer W (1973) Classification of $500 \mathrm{mb}$ patterns. Arbeitsbericht der Schweizer Meteorologische Zentralanstalt. Nr. 43

Knox PN (1996) Wiscoinsin wind data. http://www.uwex.edu/ sco/milwind.html

LADCO (1995) Lake Michigan ozone study/Lake Michigan ozone control program: project report, volume IIoverview. Lake Michigan Air Directors Consortium, Des Plaines, IL

Lyons WA, Cole HS (1976) Photochemical oxidant transport: mesoscale lake breeze and synoptic-scale aspects. J Appl Meteorol 15:733-743

Malm WK, Gebhart D, Latimer T, Cahill R, Eldred R, Pielke R, Stocker, Watson J (1989) National Park Service report on 
the Winter Haze Intensive Tracer Experiment. US National Park Service, Washington, DC

McKendry IG (1994) Synoptic circulation and summertime ground-level ozone concentrations at Vancouver, British Columbia. J Appl Meteorol 33:627-641

National Center for Atmospheric Research (NCAR), Data Support Section; and the Department of Atmospheric Sciences, University of Washington (1990) General information and user's guide for the compact disc of the National Meteorological Center grid point data set: version II. NCAR, Boulder, CO

Oke TR (1987) Boundary layer climates, 2nd edn. Methuen, London

Petersen MS, Lamb PJ , Kunkel KE (1995) Implementation of a semiphysical model for examining solar radiation in the Midwest. J Appl Meteorol 34(9):1905-1915

Robinson E, Boyle RJ (1979) Synoptic weather typing and its application to air quality in the St. Louis, Missouri area. Proceedings of the 72nd Annual Meeting of the Air Pollution Control Association, Cincinnati, Ohio, J une 24-29

Samson PH, Ragland KW (1977) Ozone and visibility reduction in the Midwest: evidence for large-scale transport. J Appl Meteorol 16:1101-1106

Seinfeld J H (1989) Urban air pollution: state of the science. Science 243:745-752

Editorial responsibility: Brent Yarnal, University Park, Pennsylvania, USA
Vukovich FM, Fishman J (1986) The climatology of summertime $\mathrm{O}_{3}$ and $\mathrm{SO}_{2}$ (1977-1981). Atmos Environ 20(12): 2423-2433

Weisensel W, Sagal M (1991) Ozone: Wisconsin's toughest air pollution problem. Air Matters (WI DNR), Summer 1991. Wisconsin Department of Natural Resources, Madison, p 1-2

WI DNR (1997) 1996 Air Quality Report. PUBL-AM-221-97. Wisconsin Department of Natural Resources, Bureau of Air Management, Madison, WI

Wolff GT, Lioy PJ (1980) Development of an ozone river associated with synoptic scale episodes in the Eastern United States. Environ Sci Technol 14:1257-1260

Wolff GT, Lioy PJ, Wight GD, Meyers RE, Cederwall RT (1977) An investigation of long-range transport of ozone across the Midwestern and Eastern United States. Atmos Environ 11:797-802

Yarnal B (1984) A procedure for the classification of synoptic weather maps from gridded atmospheric pressure data. Comput Geosci 10:397-410

Yarnal B (1993) Synoptic climatology in environmental analysis. Belhaven, London

Zhang J, Rao ST, Daggupaty SM (1998) Meteorological prpcesses and ozone exceedances in the Northeastern United States during the 12-16 J uly 1995 episode. J Appl Meteorol 37:776-789

Submitted: May 18, 1998; Accepted: J uly 8, 1999

Proofs received from author(s): N ovember 26, 1999 